\title{
Determination of Insecticide Residues in Vegetal Fruits
}

\author{
Dasciana Rodrigues, ${ }^{1}$ Tecia Carvalho, ${ }^{2}$ Anayla Sousa, ${ }^{1}$ Vicente Sousa Neto, ${ }^{3}$ \\ Pierre Fechine, ${ }^{1}$ and Ronaldo Nascimento ${ }^{1}$ \\ ${ }^{1}$ Departamento de Química Analítica e Físico Química, Universidade Federal do Ceará, Rua do Contorno, \\ S/N Campus do Pici Bl 940 CEP, 60451-970 Fortaleza, CE, Brazil \\ ${ }^{2}$ Parque de Desenvolvimento Tecnológico do Ceará, Universidade Federal do Ceará, Campus do Pici, CEP, \\ 60457-970 Fortaleza, CE, Brazil \\ ${ }^{3}$ Departamento de Engenharia Hidráulica e Saneamento, Universidade Federal do Ceará, Rua do Contorno, \\ S/N Campus do Pici Bl 713 CEP, 60451-970 Fortaleza, CE, Brazil
}

Correspondence should be addressed to Ronaldo Nascimento, ronaldo@ufc.br

Received 4 November 2010; Accepted 23 December 2010

Academic Editor: Esther Turiel

Copyright (C) 2011 Dasciana Rodrigues et al. This is an open access article distributed under the Creative Commons Attribution License, which permits unrestricted use, distribution, and reproduction in any medium, provided the original work is properly cited.

Pesticides compounds represent an important class of pollutants for food, soil and surface water resources. Thus, a simplified method using gas chromatography was used for determining five insecticide residues in fruit samples produced in Ceará State (Brazil). The insecticides were simultaneously extracted from the fruit samples with a mixture of water-methanol (1:1\%v/v) from lipid-containing crops and then reextracted with ethyl acetate. Cleanup by silica gel column chromatography was not necessary. The extracts were analyzed by GC-ECD. Analytical parameters, such as limit of detection (LOD), limit of quantification (LOQ), linearity, precision, and recovery were considered for the orange fruit. A sufficient recovery of 52.1, 57.0, 49.5, and 108.5\% for parathion methyl, malathion, chlorpyrifos, and 2,4-dichlorophenol was found. The compounds 2,4-dichlorophenol, malathion, parathion methyl, and chlorpyrifos were found in all the fruit samples analyzed.

\section{Introduction}

Pesticides are chemical substances used to kill insects and animals that destroy crops. They are characterized by pronounced persistence against chemical/biological degradation, high environmental mobility, strong tendency for bioaccumulation in human and animal tissues, and significant impacts on human health and the environment, even at extremely low concentrations [1].

Pesticides are a class of chemical substances used against organisms damaging humans, animals, and plants, such as insects, fungi, moulds, nematode, and rodents. These compounds represent an important class of pollutants for food, ground and surface water resources [2]. The majority of such substances are applied directly to the soil or sprayed over crop fields and hence released directly to the environment. The organophosphorus insecticides (OPPs) [3-7] have an important role in the agricultural pest control. However, the continued use of organophosphorus insecticides increases the possibility of residues of these compounds being found in some vegetables, threatening the alimentary security.

General population is mainly exposed to organophosphorus pesticide residues through the ingestion of contaminated foods (such as cereals, vegetables, and fruits), which are directly treated with OPPs pesticides or are grown in contaminated fields. Compared with organochlorine pesticides, OPPs demonstrate relatively low environmental persistence but a higher toxicity acute. Therefore, the OPPs residue in food has been strictly regulated by government in all countries in order to determine whether the concentrations of the pesticides used exceed their maximum residue limits (MRLs) $[8,9]$. The MRLs are established by each country and sometimes cause conflicts because different residue levels are acceptable in one country but not in another. Therefore, there is an urgent need to harmonize the different MRLs. 


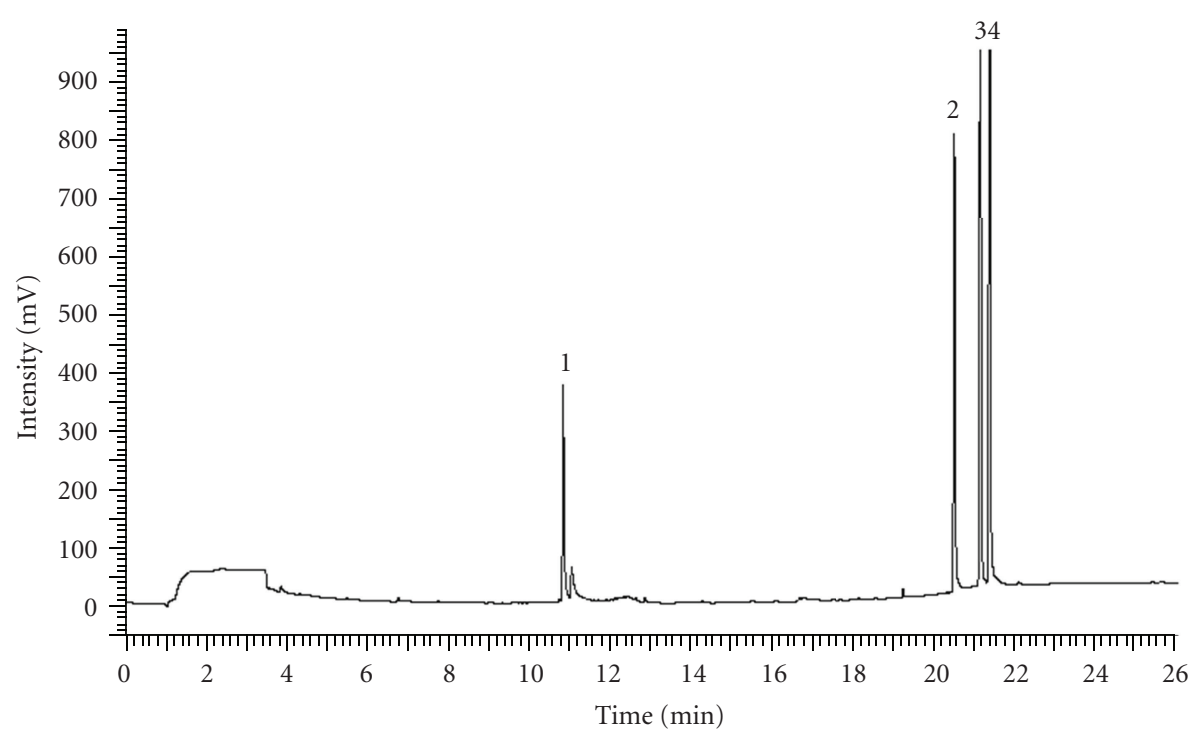

FIgure 1: Chromatogram of insecticide standards $\left(1.0 \mathrm{mg} \cdot \mathrm{L}^{-1}\right)$ in acetonitrile. Peaks $1=2,4$-Dichlorophenol, $2=$ Malathion, 3 Parathion Methyl e 4 = Chlorpyrifos.

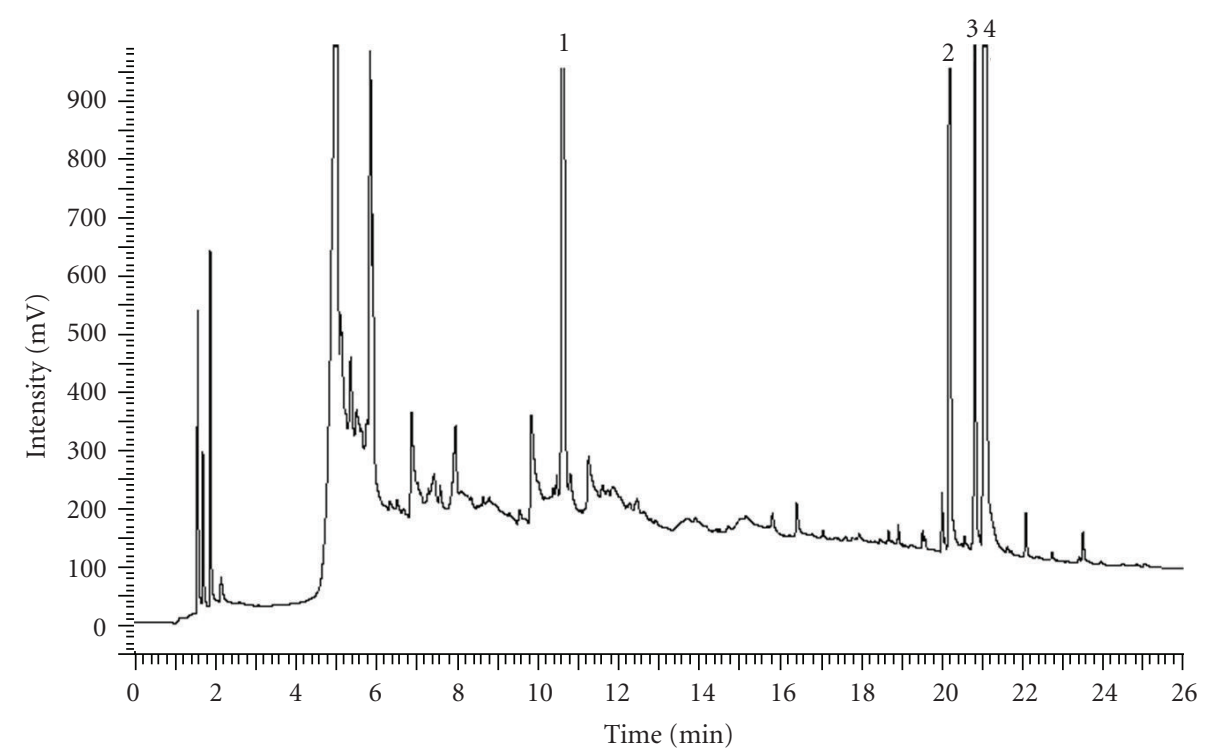

Figure 2: Chromatogram of an extracted of orange juice fortificated with insecticide standards $\left(1 \mathrm{mg} \cdot \mathrm{L}^{-1}\right)$ in Peaks $1=2,4$-Dichlorophenol, 2 = Malathion, 3 Parathion Methyl e 4 = Chlorpyrifos.

Organochlorine pesticides have been widely used worldwide since the 1940s because of their strong effects in the control of pests and diseases. Organochlorine residues and metabolites are ubiquitous in the environment because of their widespread use. Thus, the risk for human exposure and contamination is considerable.

DDT is the most popular example of organochlorine pollutants, characterized for long persistence in the environment after application $[10,11]$

In the present work, a chromatographic methodology was developed to identify and quantify some types of organochlorine and organophosphorus insecticide residues in fruit samples produced in Ceará State (Brazil).

\section{Experimental}

2.1. Sampling. Fruit samples of orange, melon, tomato, passion fruit, mango, and sugar cane juice were chosen due to their commercial importance and potential consumption. All the samples were taken twice a month for about one semester. They were purchased at State Supply Company S/A (CEASA) in Maracanaú, Ceará state. The fruits were produced in cities Serra Grande, Baraúna, Pacatuba, and Aquiraz.

2.2. Pesticides. Two different classes of common insecticides to be were investigated and structures are given in 


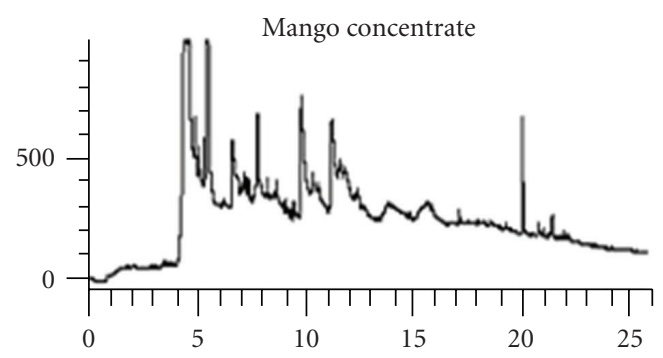

(a)

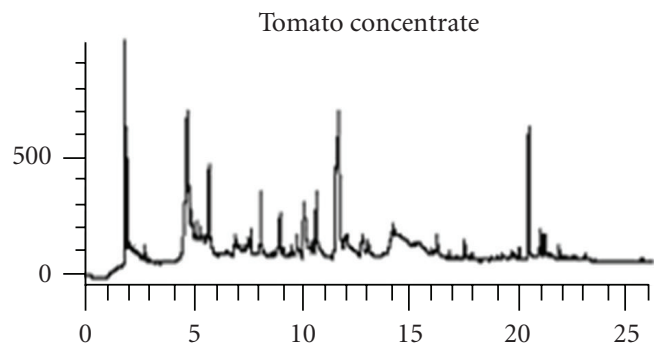

(c)

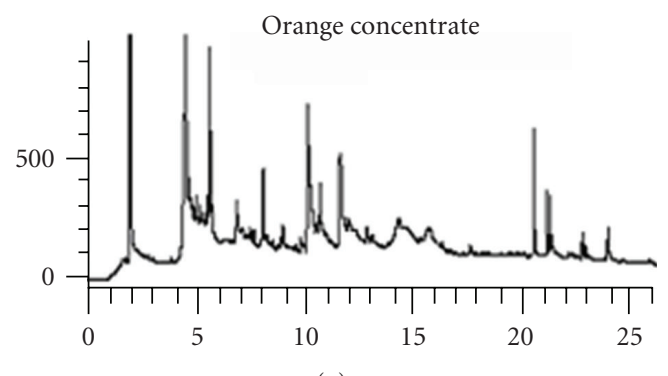

(e)

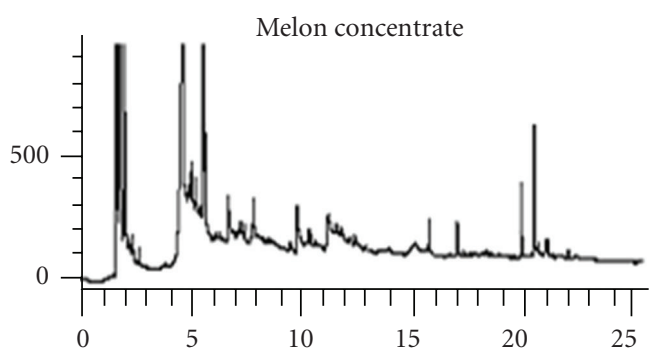

(b)

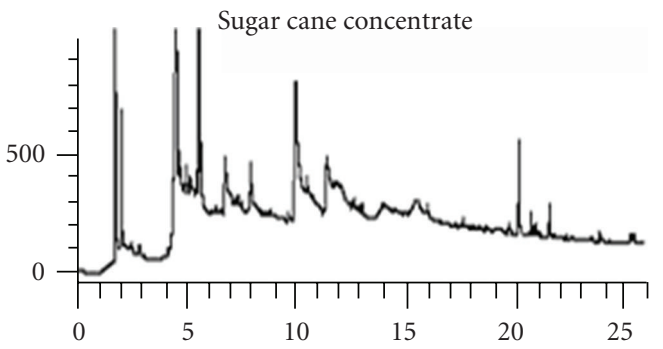

(d)

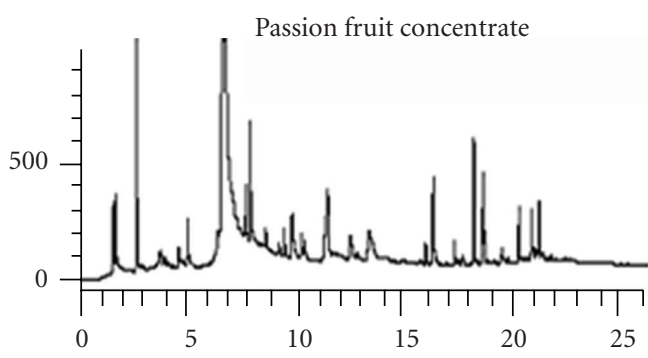

(f)

Figure 3: Chromatogram of pesticides present in different fruit samples.

TABLE 1: Insecticides investigated and toxicological class (ANVISA).

\begin{tabular}{|c|c|c|c|c|}
\hline Pesticides & Toxicological class & Structure & Agronomic class & Action mode \\
\hline Chlorpyrifo & II & & Insecticide and acaricide & Contact, ingestion, or inhalation \\
\hline Parathion Methyl & I & & Insecticide & Systemic \\
\hline Malathion & III & & Insecticide and acaricide & Ingestion or contact \\
\hline 2,4-Dichlorophenol & - & & - & - \\
\hline
\end{tabular}

Table 1, as follows: phosphorus insecticides (parathion methyl, malathion and chlorpyrifos) and organochlorine (2,4-dichlorophenol). Standard of these compounds were obtained from AGRIPEC COMPANY LTDA.

Stock solutions were prepared containing $100 \mathrm{mg} \cdot \mathrm{L}^{-1}$ of each compound investigated. Working standards were prepared by serial dilution. Final concentrations (in acetonitrile) ranged to $0.1,0.25,0.50,1.0,3.0,7.0$, and $10.0 \mathrm{mg} / \mathrm{L}$ for each analyte.

2.3. Chromatography Condition. The insecticides were identified and quantified by a gas chromatograph (Perkin Elmer Autosystem XL) equipped with an electron capture detector (ECD). These compounds were separated on column PE-17 $(30 \mathrm{~m} \times 0: 25 \mathrm{~mm}$ I.D; film thickness $0.32 \mu \mathrm{m})$. Operating conditions were as follows: initial column temperature of $45^{\circ} \mathrm{C}$ ( 2 minutes), increased at $10^{\circ} \mathrm{C} \cdot \mathrm{min}^{-1}$ to $150^{\circ} \mathrm{C}$, then finally increased to $250^{\circ} \mathrm{C}$ held for 5 minutes, and ramped at $15^{\circ} \mathrm{C} \cdot \mathrm{min}^{-1}$. The carrier gas $\mathrm{N}_{2}$ was at a flow rate of $1.0 \mathrm{~mL} \cdot \mathrm{min}^{-1}$ and injection volume of $1 \mu \mathrm{L}$ (split mode $1: 10)$.

2.4. Sample Preparation. Before the extraction process and preconcentration, the samples were made into a concentrate juice $(50 \% \mathrm{w} / \mathrm{v})$ in distillated water. Then, fresh juice was centrifuged at 4000 r.p.m. for 15 minutes, and the supernatant liquid portion was filtered through a $0.45 \mu \mathrm{m}$ nylon filter. After filtration, the juice was diluted with a water-methanol mixture $(1: 1 \% \mathrm{v} / \mathrm{v})$ and stirred by $2 \mathrm{~h}$ in a screw cap vial containing small magnetic stirrer bar. The combined extracts were transferred to a separating funnel. 
TABLE 2: Parameters of validation of the method.

\begin{tabular}{|c|c|c|c|c|}
\hline Insecticides & Linear range $(\mu \mathrm{g} / \mathrm{L})$ & $r^{2}$ & $\operatorname{LOD}(\mu \mathrm{g} / \mathrm{L})$ & LOQ $(\mu \mathrm{g} / \mathrm{L})$ \\
\hline 2,4-dichlorophenol & $0.3-2.5$ & 0.9994 & 0.23 & 0.69 \\
\hline Parathion methyl & $0.3-2.5$ & 0.9990 & 0.26 & 0.78 \\
\hline Malathion & $0.3-2.6$ & 0.9973 & 0.31 & 0.93 \\
\hline Chlorpyrifos & $0.3-2.5$ & 0.9998 & 0.25 & 0.75 \\
\hline
\end{tabular}

Table 3: Precision and recovery tests to orange fruit.

\begin{tabular}{lcc}
\hline Insecticides & Precision $(\%)$ & Recovery $(\%)$ \\
\hline 2,4-dichlorophenol & 10.0 & $108.5 \pm 9.30$ \\
Parathion methyl & 9.5 & $52.1 \pm 8.86$ \\
Malathion & 9.8 .0 & $57.0 \pm 11.8$ \\
Clorpirifos & 8.0 & $49.5 \pm 2.48$ \\
\hline
\end{tabular}

Reproducibility was calculated for three orange juices fortified per day for 3 days. Each test was analyzed in triplicate $(n=5)$.

The filtrate solution was percolated on cartridge C18 (at a descending flow rate of $2 \mathrm{~mL} \cdot \mathrm{min}^{-1}$ ). Elution was performed with $5 \mathrm{~mL}$ of ethyl acetate. Then, the sample was concentrated to dryness by evaporation under inert conditions at constant flow rate of the $\mathrm{N}_{2}$ gas. The final residue was dissolved in $1 \mathrm{~mL}$ of acetonitrile water $(4: 1 \% \mathrm{v} / \mathrm{v})$ at $\mathrm{pH}$ 4. $1 \mu \mathrm{L}$ of injection volume was used for the chromatographic system.

\section{Results and Discussion}

3.1. Method Validation. Method validation (for the orange juice) was carried out using the following parameters: limit of detection (LOD), limit of quantification (LOQ), linearity, precision and recovery. For observing the LOQ calculated as 3.LOD, see Tables 2 and 3.

Regression analysis was studied to approximate the linearity of the calibration curves. Good determination correlation coefficients were obtained for all of the compounds ranging from 0.9994 to 0.9999 (Table 2)

The limits of detection (LOD) for four insecticides were based on the lowest detectable peak that had signal/noise $=3$. The results are also listed in Table 2 . The obtained values were satisfactory and allow the determination of these compounds at the levels required to method validation. The highest LOD and LOQ values were obtained for malathion, 0.31 and $0.93 \mathrm{mg} / \mathrm{L}$, while the lowest values were 0.23 and $0.69 \mathrm{mg} / \mathrm{L}$ for 2,4-dichlorophenol, respectively.

Selectivity or the existence of potential interferences in the chromatographic determination of the pesticides in the fruit samples was monitored by running control of blank samples in each calibration. The absence of any chromatographic components at the same retention times in the target insecticides suggested that no chemical interferences occurred.

To evaluate the precision of the measurement, the reproducibility of the method was determined by performing the measurement 5 times for each spiked orange fruit samples for a 3 day period. The RSD values were found to be typically below $10 \%$. The solutions of orange fruit spiked with different amounts of target analyte were also analyzed to evaluate the recovery. The results are listed in Table 3.

The recoveries and reproducibility (RSD) varied from of $49.5 \%-108.5 \%$ and $8.0 \%-10.0 \%$, respectively, and were considered acceptable, indicating satisfactory accuracy and precision of the proposed method for determination of 2,4-dichlorophenol, chlorpyrifos, parathion-methyl, and malathion in orange fruit. These values are similar to the recoveries reported by other authors for the MSPD extraction of several pesticides from fruit juices [12-17].

3.2. Chromatography Analysis. The most frequently used detectors for pesticide residues analysis include ECD, NPD, FPD, and MSD. However, it is well known that ECD has been the most used detector in pesticide residues analysis due to its high sensitivity, in particular to halogenated pesticides although all kinds of electron-attracting functional groups such as nitro groups and aromatic structures also give a response on this detector $[12,13,18]$. Figure 1 shows a chromatogram of insecticide standards analyzed by our GC-ECD system. One can observe four peaks of the compounds studied in this work, appearing at distinct retention times. Figure 2 shows a typical gas chromatogram of an orange fruit fortification extract with a $1 \mathrm{mg} \cdot \mathrm{L}^{-1}$ of the insecticides. This chromatogram also exhibits other peaks (not identified), and one can notice the complexity of the fruit components. Therefore, the interpretation of ECD chromatograms obtained for extracts with higher amounts of ECD sensitive matrix compounds (Figure 3) can become a difficult task [12].

3.3. Determination of Real Samples. The optimized experimental conditions were applied to real samples to evaluate the efficiency of the method in the determination of each compounds investigated. The results are shown in Table 4. Average concentrations of the 2,4-dichlorophenol ranged from $1.5 \mu \mathrm{g} \cdot \mathrm{Kg}^{-1}$ (in sugar cane) to $32.1 \mu \mathrm{g} \cdot \mathrm{Kg}^{-1}$ (in tomato). This insecticide was not detected in the passion fruit. Parathion methyl ranged from $14.2 \mu \mathrm{g} \cdot \mathrm{Kg}^{-1}$ (in passion fruit) to $36.0 \mu \mathrm{g} \cdot \mathrm{Kg}^{-1}$ (in mange). Malathion was found in average concentration of around $9.2 \mu \mathrm{g} \cdot \mathrm{Kg}^{-1}$. For the sugarcane, orange, and passion fruit, malathion concentration was below LOQ. Chlorpyrifos was found in two sample, at levels ranging from $0.4 \mu \mathrm{g} \cdot \mathrm{Kg}^{-1}$ (in melon fruit) to $4.25 \mu \mathrm{g} \cdot \mathrm{Kg}^{-1}$ (in passion fruit). Chlorpyrifos concentrations in other fruits were below LOQ.

The levels of pesticides residues are controlled by Maximum Residue Levels (MRLs), which are established by each 
TABLe 4: Average distribution of the insecticide residues in fruits.

\begin{tabular}{|c|c|c|c|c|}
\hline \multicolumn{5}{|c|}{$\left(\mu \mathrm{g} \cdot \mathrm{Kg}^{-1}\right)^{*}$} \\
\hline Samples & 2,4-DCP & Parathion methyl & Malathion & Chlorpyrifos \\
\hline Sugar cane & $1.50(-)$ & $28.0(-)$ & $<\operatorname{LOQ}\left(1.0^{\mathrm{a}} ; 0.02^{\mathrm{b}} ;-\right)$ & $<\operatorname{LOQ}\left(1.0^{\mathrm{a}}: 0.2^{\mathrm{b}} ;-\right)$ \\
\hline Orange & 24.5 & $25.3(-)$ & $<\operatorname{LOQ}\left(8.0^{\mathrm{a}} ; 0.02^{\mathrm{b}} ; 4.0^{\mathrm{c}}\right)$ & $<\operatorname{LOQ}\left(1.0^{\mathrm{a}}: 0.3^{\mathrm{b}} ; 2.0^{\mathrm{c}}\right)$ \\
\hline Passion fruit & $<\operatorname{LOD}(-)$ & $14.2(-)$ & $<\operatorname{LOQ}(-)$ & $4.25(-)$ \\
\hline Melon & $2.10(-)$ & $16.6(-)$ & $<\operatorname{LOD}\left(8.0^{\mathrm{a}} ; 0.02^{\mathrm{b}} ;-\right)$ & $0.40(-)$ \\
\hline Mange & $2.16(-)$ & $36.0(-)$ & $<\operatorname{LOD}\left(8.0^{\mathrm{a}} ; 0.02^{\mathrm{b}} ;-\right)$ & $<\mathrm{LQ}(-)$ \\
\hline Tomato & $32.1(-)$ & $29.7(-)$ & $9.2(3.0)$ & $<\mathrm{LQ}(0.5)$ \\
\hline
\end{tabular}

Average concentrations. LOQ-limit of quantification. ${ }^{a}$ US MRLs, ${ }^{\mathrm{b} E U}$ MRLs, and ${ }^{\mathrm{c} B R A Z I L}$ MRLs. (-) no MRL available in USA, EU, or Brazil.

country. In Brazil the MRLs are established by ANVISA through the Program for Analysis of Pesticide Residues in Food (PARA), started in 2001, which monitors the levels of pesticides in fruits, vegetables, and grains consumed by brazilians [19]. Since not all the ANVISA's data for these insecticide residues were available during the fruit studies, it was compared with the MRLs established by the European Union (EU) and US. Different MRLs specific values are given in Table 4 for each fruit/vegetable, and the reason for it is perhaps the quantity of daily intake in average.

\section{Conclusions}

Herbicides were simultaneously extracted from fruit samples with a mixture of water-methanol and subsequent cleanup by silica gel column chromatography was not necessary. The results also show that the proposed method for the determination of chlorpyrifos, parathion-methyl, and malathion in orange fruits is simple, economical, and precise and can be used to analyze traces of insecticide residues in other too fruit samples.

\section{Acknowledgments}

The authors would like to thank CNPq, CAPES, FUNCAP, and Parque de Desenvolvimento Tecnológico do Ceará (PADETEC) for providing all facilities to carry out this work.

\section{References}

[1] H. Liu, J. Ru, J. Qu, R. Dai, Z. Wang, and C. Hu, "Removal of persistent organic pollutants from micro-polluted drinking water by triolein embedded absorbent," Bioresource Technology, vol. 100, no. 12, pp. 2995-3002, 2009.

[2] M. C. Bruzzoniti, C. Sarzanini, G. Costantino, and M. Fungi, "Determination of herbicides by solid phase extraction gas chromatography-mass spectrometry in drinking waters," Analytica Chimica Acta, vol. 578, no. 2, pp. 241-249, 2006.

[3] Y. Bai, L. Zhou, and J. Wang, "Organophosphorus pesticide residues in market foods in Shaanxi area, China," Food Chemistry, vol. 98, no. 2, pp. 240-242, 2006.

[4] J. Liu, K. Olivier, and C. N. Pope, "Comparative neurochemical effects of repeated methyl parathion or chlorpyrifos exposures in neonatal and adult rats," Toxicology and Applied Pharmacology, vol. 158, no. 2, pp. 186-196, 1999.
[5] R. K. Juhler, "Optimized method for the determination of organophosphorus pesticides in meat and fatty matrices," Journal of Chromatography A, vol. 786, no. 1, pp. 145-153, 1997.

[6] E. F. G. D. C. Dores and E. M. De-Lamonica-Freire, "Aquatic environment contamination by pesticides. Case study: water used for human consumption in primavera do leste, mato grosso-preliminary analyses," Quimica Nova, vol. 24, no. 1, pp. 27-36, 2001.

[7] A. Quintero, M. J. Caselles, G. Ettiene, N. G. De Colmenares, T. Ramírez, and D. Medina, "Monitoring of organophosphorus pesticide residues in vegetables of agricultural area in Venezuela," Bulletin of Environmental Contamination and Toxicology, vol. 81, no. 4, pp. 393-396, 2008.

[8] European Commission directive (1993) 93/58/EEC Official. Journal of the European Communities L.211/6-39.

[9] FAO, "Agriculture towards 2010," in Proceedings of the 27th Session of the FAO Conference, Rome, Italy, 1993, C 93/24.

[10] M. Suwalskya, C. Rodrígueza, F. Villenab, and C. P. Sotomayorc, "Human erythrocytes are affected by the organochloride insecticide chlordane," Food and Chemical Toxicology, vol. 43, no. 5, pp. 647-654, 2005.

[11] S. Chen, L. Shi, Z. Shan, and Q. Hu, "Determination of organochlorine pesticide residues in rice and human and fish fat by simplified two-dimensional gas chromatography," Food Chemistry, vol. 104, no. 3, pp. 1315-1319, 2007.

[12] C. M. Torres, Y. Picó, and J. Mañes, "Determination of pesticide residues in fruit and vegetables," Journal of Chromatography A, vol. 754, no. 1-2, pp. 301-331, 1996.

[13] D. Perret, A. Gentili, S. Marchese, M. Sergi, and G. D'Ascenzo, "Validation of a method for the determination of multiclass pesticide residues in fruit juices by liquid chromatography/tandem mass spectrometry after extraction by matrix solid-phase dispersion," Journal of AOAC International, vol. 85, no. 3, pp. 724-730, 2002.

[14] E. Zhao, L. Han, S. Jiang, Q. Wang, and Z. Zhou, "Application of a single-drop microextraction for the analysis of organophosphorus pesticides in juice," Journal of Chromatography A, vol. 1114, no. 2, pp. 269-273, 2006.

[15] H. G. Bolles, H. E. Dixon-White, R. K. Peterson, J. R. Tomerlin, E. W. Day, and G. R. Oliver, "U.S. market basket study to determine residues of the insecticide chlorpyrifos," Journal of Agricultural and Food Chemistry, vol. 47, no. 5, pp. 1817-1822, 1999.

[16] P. Xu, D. Yuan, S. Zhong, and Q. Lin, "Determination of organophosphorus pesticides and related compounds in water samples by membrane extraction and gas chromatography," Environmental Monitoring and Assessment, vol. 87, no. 2, pp. 155-168, 2003. 
[17] Y. Xi and H. Dong, "Application of solvent sublation for the determination of organophosphorous pesticides in vegetables by gas chromatography with a flame photometric detector," Analytical Sciences, vol. 23, no. 3, pp. 295-298, 2007.

[18] H. J. Stan and B. Christall, "Residue analysis of onions and other foodstuffs with a complex matrix using twodimensional capillary-GC with three selective detectors," Fresenius' Journal of Analytical Chemistry, vol. 339, no. 6, pp. 395-398, 1991.

[19] Agência Nacional de Vigilância Sanitária, http://www.anvisa .gov.br. 


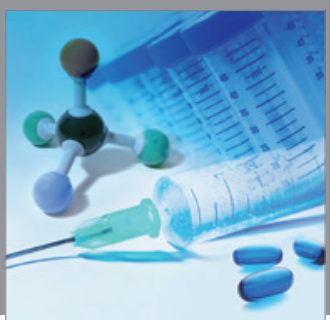

International Journal of

Medicinal Chemistry

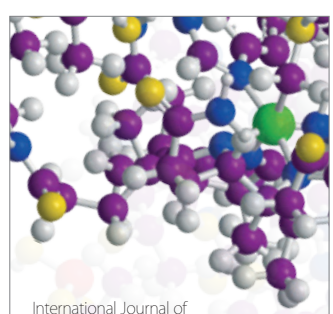

Carbohydrate Chemistry

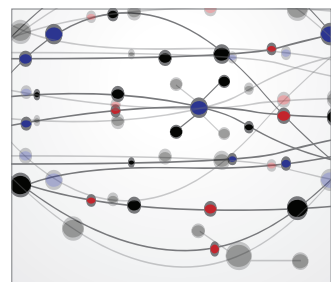

The Scientific World Journal
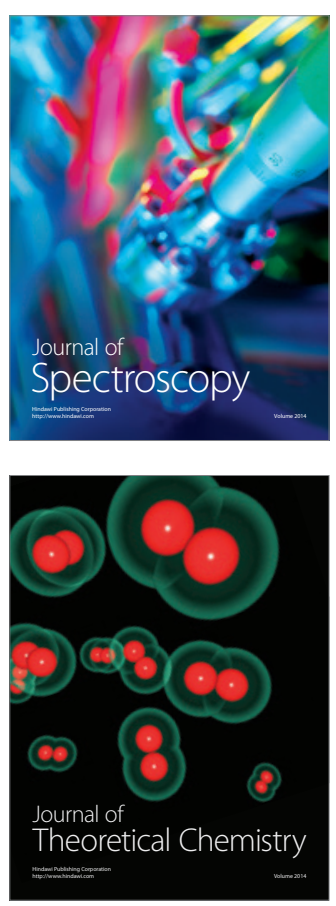
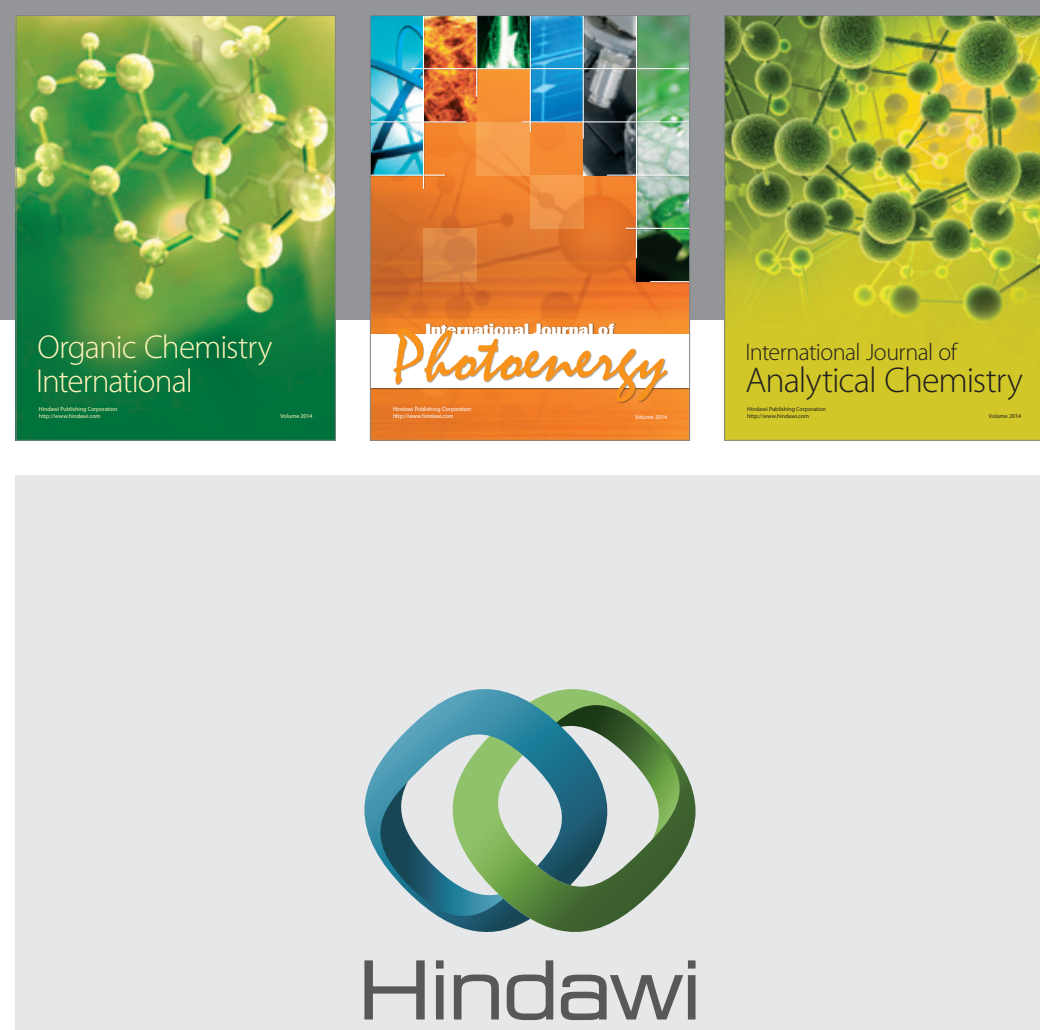

Submit your manuscripts at

http://www.hindawi.com
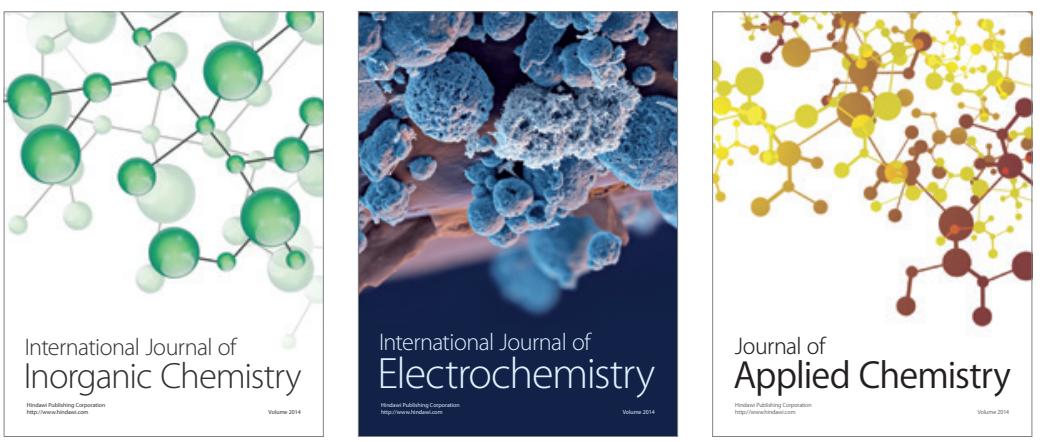

Journal of

Applied Chemistry
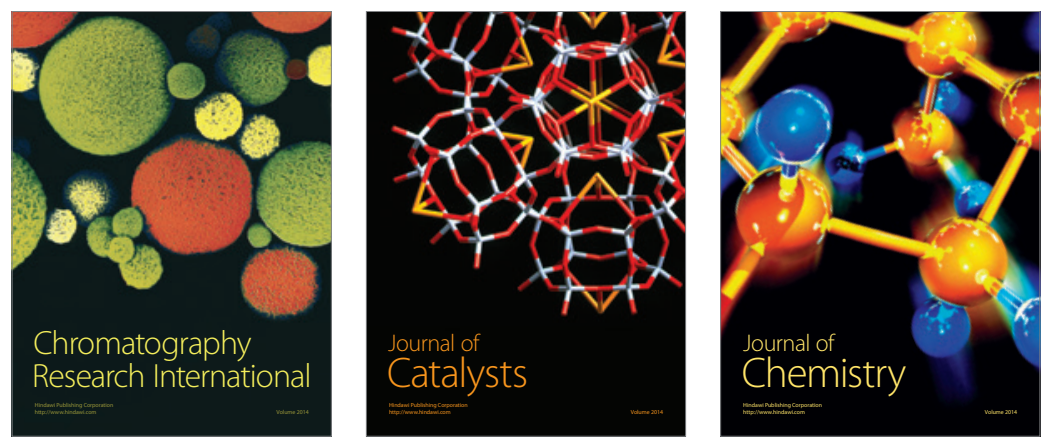
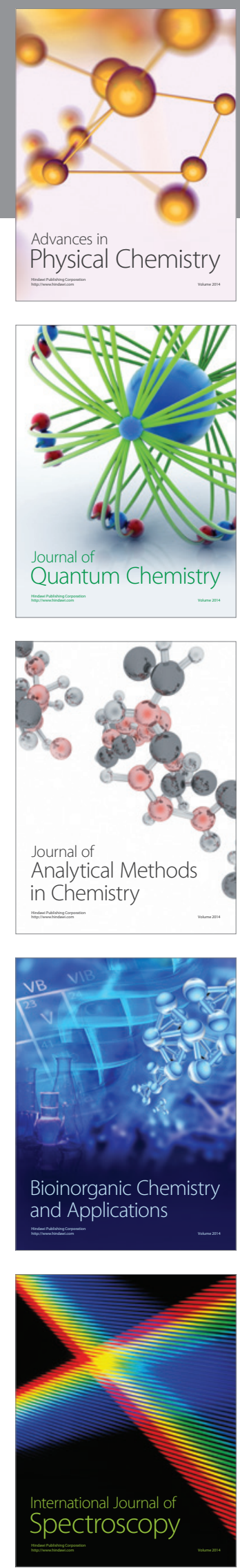